\title{
The Viable System Model for Diagnosing and Handling IT-Project Interdependencies in Large Portfolios
}

\author{
Sameer Bathallath, Stockholm University, Kista, Sweden \\ Åsa Smedberg, Stockholm University, Kista, Sweden \\ Harald Kjellin, Stockholm University, Kista, Sweden
}

\begin{abstract}
Adequately considering project interdependencies has shown to be a determinant of how successful IT/IS project portfolios are managed. However, this can be especially troublesome since there is no universal way to handle many project interdependencies that continue to change over time due to environmental uncertainty or unexpected decisions. This can seriously disrupt portfolio performance. In this article, the authors used the systems perspective to address the problem of managing multiple IT-project interdependencies in complex IT/IS portfolio environment. In particular, the authors propose using the cybernetic model Viable System Model to facilitate thinking and reasoning concerning the difficulty of managing IT-project interdependencies. To validate their approach and to ensure the appropriateness of it, the authors used real-world problem situations drawn from multiple case studies conducted in four leading organizations in Saudi Arabia. The findings support that the Viable System Model can be applied to assist in diagnosing and handling of IT-project interdependencies.
\end{abstract}

\section{KEYWORDS}

Complexity, IT Projects, Project Interactions, Project Interdependencies, Project Interdependency Management, Project Management, Project Portfolio Management, The Viable System Model, VSM

\section{INTRODUCTION}

To date, most IT/IS Project Portfolio Management (PPM) research has been focused on how to identify, evaluate and prioritize projects that can contribute to organizational objectives. This, in turn, gave rise to various approaches, such as those proposed in (Anantatmula \& Webb, 2014; Bardhan \& Sougstad, 2004; Eilat, Golany, \& Shtub, 2006; Fliedner \& Liesiö, 2016; Killen \& Hunt, 2013; Killen, 2017; Medaglia, Graves, \& Ringuest, 2007; Verma \& Sinha, 2002), to help making portfolio choices more efficient. At the heart of this quest has been an emphasis on how to design project interdependencies to secure their synergistic effects on portfolio performance. For example, a project portfolio aimed at delivering new banking services may benefit more from sharing knowledge that could be later incorporated to develop more innovative services. As this example implies, the interdependencies 
between projects can play a vital role in bringing about increased benefits, and thus contribute to portfolio success in one way or another. Despite the widely recognized importance of project interdependencies (PIs) in the context of IT/IS project portfolios, little is known about how PIs can be managed efficiently when they get more and more complex. This can seriously disrupt work in the portfolio. Thompson (1967) was a pioneer in drawing attention to interdependencies in organizational systems. Thompson categorized interdependencies into three forms representing different degrees of contingency: pooled, sequential, and reciprocal. In pooled interdependency, each organizational unit contributes independently to and is supported by the whole organization. To the contrary, in sequential interdependency an output of one organizational unit is an input for another unit, while in reciprocal interdependency each unit's output is input for the other units. Pooled interdependencies can be handled using standardized routines while sequential and reciprocal interdependencies can be handled using schedules and plans, and mutual adjustments respectively (Thompson, 1967). In this sense, managing a multitude of interproject dependencies with varying degrees of complexity can become overwhelming and very difficult to handle (Fliedner \& Liesiö, 2016). Several other authors have noted that the complexity of the project portfolio increases by a number of factors including: number of projects, the degree of interdependency between the projects, and the magnitude and frequency of change in projects and interdependencies (Blecic, Cecchini, \& Pusceddu, 2008; Danilovic \& Browning, 2007; Teller, Unger, Kock, \& Gemünden, 2012; Voss \& Kock, 2013). However, only a few authors have offered to examine the complexity aspects of managing PIs. For example, Bardhan, Bagchi, \& Sougstad (2004) introduced a model that accounts for the complexity in valuing project portfolios while considering the impact of PIs on portfolio value. Another author (Killen, 2013) found that graphical representations of projects and their interdependencies can help in identifying and reducing the complexity of managing these interdependencies. Despite the efforts to incorporate PIs in many approaches it remains unclear how to overcome the complexity of managing these interdependencies along the PPM lifecycle and further handle them during unexpected events.

Our previous work notes that PIs often create challenges for the manageability of IT/IS project portfolio (Bathallath, Smedberg, \& Kjellin, 2016a, 2016b, 2017). We empirically found that insufficient understanding of human responsibilities in the whole portfolio and unpredictability of the environment and technology constraints can be a source of increasing difficulty of managing IT-PIs in different IT/IS project portfolio contexts (Bathallath et al., 2017). In a recent study, we concluded that critical systems thinking and the cybernetic model Viable System Model (Beer, 1985) can be used to identify where, when and how interdependencies occur and thus support in quantifying, describing and managing them (Bathallath et al., 2016b). This study is part of a continuous effort on how the complexity resulting from PIs can be effectively managed.

\section{RESEARCH QUESTION}

In connection to the previous section, the study reported in this article addresses the importance of PIs in achieving PPM success. This entails challenges including those dealing with multiple PIs that continue to change over time due to environmental uncertainty or unexpected decisions. Failure to consider PIs may throw the portfolio off balance and hence the viability of the portfolio can be significantly affected. The viability of systems, according to Beer (1985), holds that for any system to stay viable it should maintain a flexible structure capable of adapting to its environment while maintaining its inter-element connectivity. Thus, we aim at investigating an efficient way to manage IT-PIs, thereby maintain the viability of the portfolio. The research question that this study puts forward is: How can multiple project interdependencies within a portfolio of IT/IS projects be effectively diagnosed and handled?

The paper is organized as follows. In the next section, the research method is discussed, followed by a comprehensive literature review on the topics included in the study. Afterwards, the empirical 
outcomes of the study are reported, followed by discussion section. Finally, the last section concludes the paper and provides suggestions for future research.

\section{RESEARCH METHOD}

As previously described, the research addresses the manageability of IT-PIs in an environment of uncertainty and change. It aims to advance IT-PPM implementation by enhancing management ability to diagnose and handle IT-PIs in a more efficient way. To study this issue and have a better understanding of the managerial challenges specific to the management of the IT-PIs, a combination of two research methods was employed. First, a literature review was performed to explore available theoretical and empirical work on managerial challenges concerning IT-PIs. The search was conducted, for the years 2000-2015, using a standard systematic approach (Webster \& Watson, 2002). The review results are presented in another study by the same authors (Bathallath et al., 2016a). Second, a qualitative multiple-case study was conducted to investigate real-world situations involving complex IT-PIs. The data was collected by means of semi-structured interviews with senior and middle management within four leading companies in Saudi Arabia. The companies were selected using purposeful sampling (Richards \& Morse, 2012) from a variety of industries in Saudi Arabia. Both, company size and total annual IT budget were adopted as criteria for selecting the companies. In total, a number of seven companies were first approached. Out of those, only four have relied on PPM as a management methodology. Among them were two from the service provider industry (a telecom company and a bank), while the other two companies represented a government agency and a petrochemical company. For each company, two respondents from senior and middle management were approached. Respondents from senior management were chosen based on two criteria: (1) years of work experience in IT-PPM (at least 6 years) and (2) their job roles and responsibilities. The interviews were conducted and processed through the following procedure: (a) respondents from senior management were interviewed first to obtain information concerning PPM and interdependency related issues (questions are listed below); (b) all interviews (except one) were recorded with informed consent, transcribed and classified into a system of codes; (c) transcribed data were then arranged under three key themes including: PPM-related activities, confronted problem situations involving PIs and prescribed remedies; (d) each problem situation was further analyzed based on two major criteria: the form of the interdependency between the projects (sequential and reciprocal interdependencies were only considered) and financial/time impact; (e) a single problem situation (with highest financial/time impact) from each company was selected; (f) respondents from senior management were again approached, briefed about the selected problem situations and asked to nominate two other people (at least project managers) who were involved in the situation; (g) a total number of nine people were nominated (two from each company except for the telecom company who nominated three); (h) nominees were then approached and asked to participate; (i) out of those approached only one from each company has agreed to participate; (j) interviews were conducted by telephone conference, detailed notes were taken, transcribed and analyzed.

The interviews with senior managers were guided using semi-structured questionnaires. Specifically, four question themes were considered: (1) applied PPM approach, (2) types and forms of IT-PIs, (3) confronted problems involving PIs, causes of the problems and how each problem was dealt with, and (4) resulted financial/time impact(s) on the portfolio. The interviews with the other managers were guided by the following question themes: (1) the situation before and after the problem arose, (2) the impact of the problem on the projects and the PIs (3) how the problem was analysed and handled, (4) what impact the problem has on the portfolio.

For the analysis of data, we adopted cybernetics and systems theory. The choice was based on the work of (Aritua, Smith, \& Bower, 2009) who argued that project portfolios have the characteristics of complex adaptive systems and that systems thinking can provide a novel way of understanding organizational complexity. Specifically, we adopted the cybernetic model Viable System Model (VSM) 
(Beer, 1985) for the following reasons: (1) the VSM is a powerful tool that helps to gain deep insight into the organizational system in focus and to describe its constituent components (Espejo \& Reyes, 2011; Espejo, 1994), (2) the VSM helps to identify and gain understanding of multi-level systems and interdependencies between different systems' components (Espejo \& Reyes, 2011; Jackson, 1991) (i.e. the model can be applied recursively to describe and analyze interdependencies within the portfolio (Bathallath et al., 2016b)), and (3) the VSM "helps contextualizing the symptoms that people experience as they try to make sense of problematic situations" (Espejo \& Reyes, 2011, p. 214).

\section{EXTENDED BACKGROUND}

In this section, we first provide an overview of some basic concepts of PPM to identify areas of concern regarding the subject of this study. This is followed, in the second part, by an extensive overview of the IT/IS literature on project interdependency and project interdependency management. In the third part, we provide a background on the viable system model to motivate the choice of the model for the analysis part of the study.

\section{An Overview of Project Portfolio Management}

This subsection provides a short background on PPM concept and narrow down the focus on PPMrelated processes. This will serve as a foundation to discuss areas of concern regarding project interdependency and project interdependency management. In general, project portfolio management can be defined as a dynamic process primarily concerned with formulating, optimizing and maintaining a pipeline of projects to achieve certain business objectives (Daniel, Ward, \& Franken, 2014; Killen \& Hunt, 2013; Kundisch \& Meier, 2011). It involves activities such as continuously updating and revising existing projects, evaluating and prioritizing new projects, coordinating projects, handling the interdependencies among projects, and responding to environmental changes (Cooper, Edgett, \& Kleinschmidt, 1999; Levine, 2010). Bible \& Bivins (2012), divided the PPM process into a sequence of activities organized around three central phases: strategic planning, screening and selection, implementation and evaluation.

\section{Strategic Planning}

In this phase, the organization will have to revise and update its strategic plan to account for environmental changes (Bible \& Bivins, 2012; Parry \& Lind, 2016). It involves setting strategic goals and objectives for the portfolio and associating these objectives with criteria for later selection and prioritization of projects.

\section{Screening and Selection}

This phase is generally where projects are selected, evaluated, prioritized and formally approved to be in the portfolio. Potential projects are first proposed by various levels of the organization. Projects are then screened against predetermined selection criteria to make final selection decision. This is followed, in the selection phase, by making go/kill decision on individual projects through careful analysis of the projects that have passed the screening process together with the projects that were already underway (Bible \& Bivins, 2012).

\section{Implementation and Evaluation}

The implementation phase includes the actual initiation of project activities (including those related to project interactions) that go into developing the portfolio. The evaluation phase, which runs together with the implementation phase, serves to assess project and portfolio performance, and make necessary adjustments (e.g. adding, modifying or removing projects) (Bible \& Bivins, 2012). This in turn could lead to changes regarding the interdependencies (i.e. removing, adjusting, or adding 
new interdependencies) between the projects (Cooper, Edgett, \& Kleinschmidt, 2001; Killen, Hunt, \& Kleinschmidt, 2007; Levine, 2010; Rank, Unger, \& Gemünden, 2015).

\section{An Overview of Project Interdependency and Project Interdependency Management}

This section reviews basic concepts of project interdependency and project interdependency management. This will help to distinguish between various kinds of PIs, shed light on some of their characteristics, and highlight complexity aspects of managing them. In general, interdependencies may take place between projects when one project is partially or wholly being influenced by another project(s) for its development (Bathallath et al., 2016a) or, simply put, when "the success of a project depends upon other project(s)" (Killen \& Kjaer, 2012). To secure that projects are designed to facilitate positive interdependencies the interdependencies should be seen as a negotiation and collaboration process that gives rise to new forms of synergies to maximize the portfolio value (Ghaffari \& Emsley, 2017; Nyfjord, Bathallath, \& Kjellin, 2014; Pons \& Haefele, 2016). Among the benefits that could be generated from projects being interdependently bound to one another are economic benefits (e.g. cost savings, resource optimization, etc.) and strategic benefits (e.g. learning and knowledge diffusion, innovative products, etc.). However, PIs may lead to negative effects such as: resource waste caused by wrong allocation of portfolio resources among projects (Aritua et al., 2009; Rungi \& Hilmola, 2011), schedule slippages and cost overruns (Formentini \& Romano, 2011; Lee \& Kim, 2001; Rungi \& Hilmola, 2011), and inter-project competition for resources (Engwall \& Jerbrant, 2003). IT-PIs within IT/IS project portfolios can be structured along three generic dimensions (Bathallath et al., 2016a): interdependency type, form and pattern of interaction comprising each interdependency, and cost/benefit outcome of each. In the first dimension, various types of PIs were discussed in the IT/IS literature, such as resource, technology, outcome, knowledge/learning and marketing interdependencies. More details about different types of IT-PIs can be found in (Bathallath et al., 2016a). The second dimension concerning the structural aspects of PIs (i.e. forms and patterns of interaction), Thompson (1967) differentiated between three forms of organizational interdependencies each of which represents different degree of contingency (pooled, sequential and reciprocal) and each can be managed by different coordination mechanisms. The third dimension (cost/benefit) is related to the outcomes produced by each project interdependence. In this dimension, Kundisch \& Meier (2011) distinguished between six different patterns of project interactions that lead to different economic effects on the portfolio.

\section{The Concept of Portfolio Complexity and the Viable System Model (VSM)}

This subsection offers an overall view on the concept of portfolio complexity, followed by a description of Beer's (1985) Viable System Model (VSM) which is later adopted in the analysis of the data collected. The adaptability of the organizational system to effectively manage multiple projects and handle their need to interact with one another has been extensively studied in the project management literature. For the majority of these studies, dealing with the complexity aspects of the interactions between projects is considered to be one of the most pressing research questions. Teller et al. (2012) applied systems perspective to describe the complexity of project portfolios and stressed the need to consider contingency factors in PPM research. This falls in line with the findings by Aritua et al. (2009) who claimed that "project portfolio environments exhibit the characteristics of complex adaptive systems" (Aritua et al., 2009, p. 72). The portfolio was portrayed as a system, comprised of interrelated parts, emergent in a sense that the system as a whole is greater than the sum of its parts, adaptive to changing environment, self-organized, non-linear and responsive of feedbacks (Aritua et al., 2009). On this view, a project portfolio is considered as made up of interrelated projects that together form a whole system. This implies that the portfolio as a whole is greater than the sum of its projects, where the goal of the portfolio (the system) is to remain efficient, autonomous and viable within its environment (Churchman, 1968; Schoderbek, Schoderbek, \& Kefalas, 1990). For Beer 
(1985), if the organization is to retain viability it has to adjust continually and adapt to its environment i.e. it has to strive for "requisite variety."

The viability of the project portfolio can be diagnosed with the VSM (Beer, 1985). In essence, the model is made up of basic functions that together represent the basis for any system to stay viable: operations, coordination, control, audit, intelligence and policy (see Figure 1). The model has a recursive structure, which means that the system-in-focus can shift from a whole portfolio to autonomous units at a lower level of recursion (e.g. projects, sub-projects, sub-sub-project, etc.) or to units at a higher level of recursion (e.g. a large-scale portfolio consisting of several portfolios).

The VSM (as illustrated in Figure 1) can be outlined as follows: the operations of the portfolio are responsible for the execution of all tasks and activates over the portfolio life cycle. Coordination refers to shared models, norms, and values that support projects' operational coordination of their actions (Espejo \& Reyes, 2011). It also includes project collaboration and interaction, over a shared sphere of operations, to maximize value creation and optimize resource allocation across the portfolio. The portfolio coordination function cuts across interrelated projects throughout the portfolio. Other functions in the system (control, audit, intelligence and policy) are related to the management of the project portfolio and, more important, to observe and react to the environment in which it is

Figure 1. The Viable System Model (adapted from Beer, 1985, p. 139)

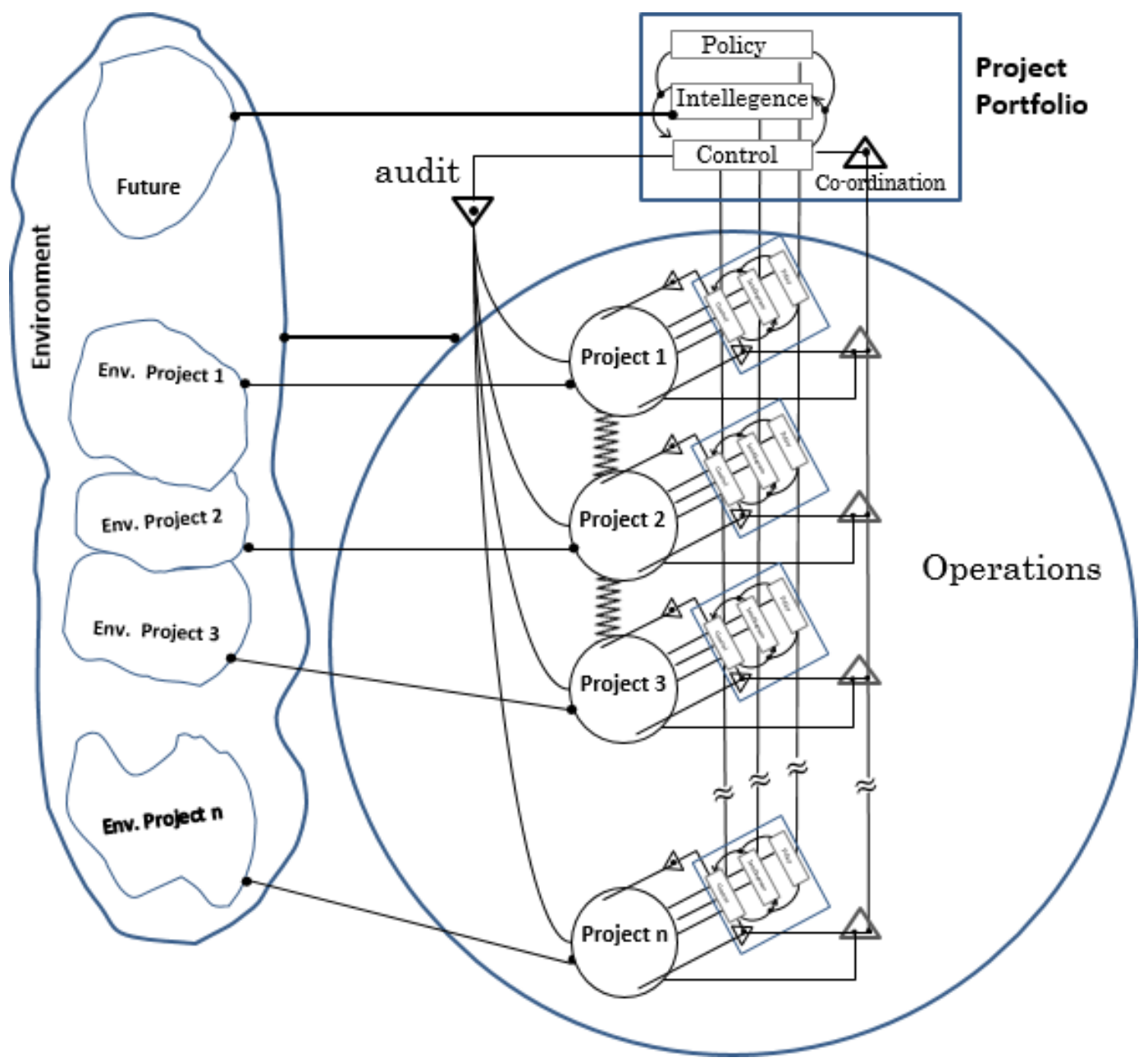


located. While intelligence is important for making the portfolio more adaptive to the changes in the environment, control and audit functions are needed for internal stability of the portfolio (for planning, scheduling and tracking projects, report on results, distributing resources, implementing change, etcetera). Policy function is necessary for maintaining equilibrium between internal stability and change in order not to disturb the balance of the whole portfolio.

\section{EMPIRICAL OUTCOMES}

In this section, we present the results obtained through case studies and in-depth interviews with eight project management office (PMO) members of four organizations in Saudi Arabia. The selection of organizations was guided by means of purposeful sampling using, as criteria, total number of projects in the portfolio and annual IT budget. Eight interviewees, two from each company, were selected based on their total years of experience in IT project management and their role in dealing with PIs. Each interview took between 60 and 80 minutes, was audio recorded and each interviewee was provided with a consent form. The interviews were guided using semi-structured approach. A list of predefined question themes was designed to gain deep information on the project portfolios at the four organizations and the challenges posed by IT-PIs. Table 1 summarizes the data of the organizations and the interviewees involved in the study.

In the remaining part of this section the findings drawn from the interviews will be presented. Findings revealed a total number of sixteen cases (involving different kinds of PIs) as follows: Org1 (6 cases), Org2 (3 cases), Org3 (3 cases) and Org4 (4 cases). A total number of four cases (one from each organization) were chosen based on two criteria: the form of the interdependency among the

Table 1. Background information on the organizations and the roles interviewed

\begin{tabular}{|c|c|}
\hline Organization & Organization Background \\
\hline $\begin{array}{l}\text { Org. } 1 \\
\text { Telecom company }\end{array}$ & $\begin{array}{l}\text { A leading telecommunication service provider in Saudi Arabia and among the three top telecom providers in the middle } \\
\text { east with a customer base exceeding } 3 \text { million customers. The market environment, in which the company operates, is } \\
\text { considered extremely competitive and highly controlled by regulatory forces. The company runs, in average, a portfolio } \\
\text { consisting of more than } 250 \text { IT-projects ranging from small infrastructure to large-scale software development projects. The } \\
\text { projects are organized under seven core programs, out of which four constitute different lines of telecommunication services } \\
\text { (mobile, home, data and wholesale). The remaining three programs are dedicated to IT infrastructure, customer information } \\
\text { management and shared services. } \\
\text { PPM methodology and tools: Visual displays of projects and PIs (visual project maps); Special project management tool kit, } \\
\text { Enhanced Telecom Operations Map (ETOM) } \\
\text { Interviewees: PMO Director, Project Manager }\end{array}$ \\
\hline $\begin{array}{l}\text { Org. } 2 \\
\text { Banking and finance } \\
\text { services company }\end{array}$ & $\begin{array}{l}\text { The company is one of the largest banking and financial services provider in Saudi Arabia with more than } 2 \text { million } \\
\text { customer base. At the time of the study, the company was expanding its product/service range to reach more customers and } \\
\text { maintain its market position. The market environment where the company operates is characterized by intense competition } \\
\text { and high regulatory pressure. The PMO at the company is responsible for managing a portfolio consisting of four major } \\
\text { sub-portfolios with more than } 200 \text { projects in total. This includes the responsibility for creating project plans, coordinating } \\
\text { project relationships, reinforcing existing products/services and driving new products/services to market. } \\
\text { PPM Methodology and tools: Matrix representation of projects (Dependency Structure Matrix); Microsoft Project, } \\
\text { Accelerated SAP } \\
\text { Interviewees: PMO Director, Project Manager }\end{array}$ \\
\hline $\begin{array}{l}\text { Org. } 3 \\
\text { Government agency }\end{array}$ & $\begin{array}{l}\text { A specialized government agency dedicated to develop IT turnkey solutions (e.g. e-government portal, resource } \\
\text { management, complaint handling) to a number of government agencies. The agency runs a portfolio consisting of more than } \\
50 \text { IT-projects grouped under } 4 \text { major programs. Almost all of the projects included in the portfolio are interrelated with } \\
\text { each other for the consideration of delivering an integrated e-government platform that supports government reforms and } \\
\text { initiatives. At the time of the study, the PMO was under pressure to deliver multiple applications to customers on time and } \\
\text { within budget. } \\
\text { PPM Methodology and tools: Visual displays of projects and PIs (visual project maps); Microsoft Project } \\
\text { Interviewees: Program Manager, Project Manager }\end{array}$ \\
\hline $\begin{array}{l}\text { Org. } 4 \\
\text { Petrochemical } \\
\text { company }\end{array}$ & $\begin{array}{l}\text { An oil and gas company with over 3,500 employees and a footprint in some parts of the world. The company has a project } \\
\text { portfolio management office (PPMO) that manages a portfolio consisting of more than } 70 \text { IT-projects (divided between } \\
\text { two sub-portfolios). The PPMO, among other things, is responsible for implementing an ERP solution to support company } \\
\text { efforts in extending its operations. } \\
\text { PPM Methodology and tools: Primavera Enterprise Project Portfolio Management; Microsoft Project, Accelerated SAP } \\
\text { Interviewees: PPMO director, Project Manager }\end{array}$ \\
\hline
\end{tabular}


projects (only sequential and reciprocal interdependencies were considered), and the financial/time impact that the problem situation had on the portfolio.

\section{Case 1}

The director in Org. 1 described inability to anticipate future market directions concerning customer demand for new telecommunication services. Hence, it was almost impossible to determine beforehand what projects and interrelationships that would serve the organization the best. As the director mentioned: "Not having enough information about future market directions makes it difficult to decide what projects to incorporate in the portfolio, and consequently it became impossible to decide how projects might relate to one another." The director also indicated that the majority of the projects in the portfolio were mutually dependent on each other, since there is often an element of shared resources/activities across the projects in the portfolio. On the same issue, the project manager commented: "It is extremely difficult to put together, in advance, all possible projects and determine the interdependencies that might add value to the portfolio, since business requirements change frequently. Competitors' moves can also signal changes in the strategy concerning both new and existing services. Therefore, certain projects in the portfolio will continue to change over time." As a solution to the aforementioned situation, the director mentioned that "a group of people from different functions (project management, marketing and sales, IT, and the operations) and diverse backgrounds were required, by top management, to meet on a monthly base to brainstorm, discuss and generate new service ideas. This has helped us create a shared space for thinking about possible service/project scenarios and hence secure that potential projects and of course interrelationships between these projects are identified."

\section{Case 2}

The director in Org. 2 described a situation of change in project scope due to expansion and change in business requirements. This, in turn, caused confusion and conflict to other ongoing projects in the portfolio, adding extra workload on the affected projects. When asked about the case, the project manager commented: "The change in project scope has forced five other projects in the portfolio to deal with the trouble of trying to cope with the increased workload, since all of the six projects were highly interdependent on each other and had to be executed in parallel to develop a solution for handling customer complaints." Regarding the affected PIs, the project manager said: "The interdependencies between the projects have involved many activities like sharing of senior experts, sharing the design and development of certain software components, sharing the IT infrastructure, and sharing the budget. After the change in project scope has taken place, nearly all dependent projects on that project went into a conflict of trying to adjust to the new requirements. This in turn caused confusion and loss of control over all ongoing activities between these projects." It is important to mention that most of the interdependencies described by the project manager were of a reciprocal nature. In reaction to the problem situation, the director made a decision to temporarily suspend the project to avoid project overload and loss of productivity. The director explained: "To deal with the problem, we first stopped the project together with all other affected projects in the portfolio. This is to evaluate the impact that the changed project scope has on the rest of the projects. In turn, this change has resulted in a demand for extra budget and extra activities between the projects." The consequence of these changes has been that all six projects were compined into a standalone program. This was, as indicated by the director, to gain control and enhance communication and coordination of activities among the projects.

\section{Case 3}

The program manager in Org. 3 described a technical problem in a project (for developing multiple web-based applications) that led to schedule and cost overruns in another project (for training employees on using the applications) in the same portfolio. As the program manager mentioned: 
"The application project was mainly concerned with developing a number of applications for use by employees to coordinate evaluation activities within the organization. The project faced a major technical problem in the application server, which could not be easily fixed unless the server was replaced. This in turn resulted in a delay of the training project, since the applications were necessary for the training project to start on time." Regarding the nature of the interdependency between the two projects and how the situation was handled, the project manager said: "The applications were required to be operational before the training project could start, since it was crucial to provide employees with a hands-on training on real-life system. We realized that the problem could not be resolved within a reasonable period of time. Therefore, we decided to host the applications in a third-party server so that the training project can be started as quickly as possible." Regarding how the coordination between the projects was organized, the program manager mentioned: "We usually rely on a master plan that sets out clearly all activities that must be undertaken to keep the projects and the program on track. Project managers rely most on interpersonal relationships to coordinate their project activities. This way of coordination did not work sufficiently well since people in the training project were unaware of what had happened in the other project, although the technical problem concerning the server was discovered at an early stage."

\section{Case 4}

The PPMO director in Org. 4 described a situation of integrating various subsystems/components across two interdependent projects (in the same portfolio) to come up with a solution for intra-company work management. The project manager described the interdependency between the two projects and how the integration of components was performed. The discussion revealed a reciprocal form of interdependency in which teams from both projects were brought together to develop, test and deploy the intended solution. Parts of the components were supplied by vendors who did not adhere to strict technology standards. As the program manager mentioned: "There is often a broad variety of technology options available to every project in the portfolio. This sometimes makes it hard to integrate components that are supplied through different vendors. For a time, we faced a problem with integrating different software components that were partly supplied by vendors who did not adhere to strict technology standards." With regard to the impact on the portfolio, the project manager mentioned: "We did not realize the problem until we tested the software (the final solution) before it became operational. During the test we discovered a high error rate in the data generated by one of the subsystems, which turned out to be highly critical to the final solution. We found that part of the components, supplied by one of the vendors, did not comply with the guidelines of technical standards. As a consequence, the work in the two projects came to a standstill for several weeks, causing delays and additional investments." As a solution to the aforementioned problem, the program manager mentioned: "We decided to replace the faulty components with another from a renowned vendor. However, to avoid facing similar problems in the future we decided to base our choices of technologies on those recognized as "best practices."

\section{DISCUSSION}

In this section, we first adopt the VSM to describe PPM-related processes, right from the strategic planning phase of the portfolio till the portfolio moves into later stages of development. This is to provide an overall picture of what PPM consists of and thus provides the basis for later analysis of the four problem situations encountered by the approached companies.

\section{A Systems Description of PPM-Related Processes}

Taking the view that project portfolios have the characteristics of complex adaptive systems (Aritua et al., 2009) and that organizations are adaptive structures that strive for stability and viability (Beer, 1985; Jackson, 1991; Schoderbek et al., 1990), the strategic planning phase of a portfolio represents 
a foundational step in aligning the portfolio to corporate strategy. It entails identifying opportunities and threats posed by the external environment as well as strengths and weaknesses of the internal environment. In this respect, the policy function of the wider organization (i.e. the corporate at recursion level 0, see Figure 2), with reference to the VSM has to ensure that the portfolio as a whole is aligned to predefined criteria determined by the corporate management. Alongside policy management, the intelligence function (at corporate level) has to continuously observe variations in the external environment like, for example, sudden moves of competitors. The sole purpose of the intelligence function is to protect and enhance corporate ability to respond to uncertainties in the business environment. For example, market surveys can be helpful in spotting market opportunities and trends. On the other hand, both control and audit functions (at the corporate level) are responsible for planning and reviewing corporate strategies including those related to what the portfolio is expected to deliver and how the projects should be evaluated and assigned to the portfolio. This has to go in line with an appropriate distribution of resources across the portfolio to support the projects and follow up on the results. At this level of recursion, coordination is crucial to maintain connectivity and collaboration among corporate subunits, therefore assure organization-wide cohesion and consensus about overall portfolio objectives.

Going from corporate level down to portfolio level (recursion level 1); the policy function (of the portfolio) will have to ensure strategic alignment of the portfolio with corporate strategy, meanwhile maintain a balance between its internal stability and changes imposed by the external environment. At this level of recursion, the primary task of control and audit is to maintain portfolio progress through proper planning and release of resources across the portfolio. Audit is essential to identify bottlenecks and report on all active projects' activities (including project interactions) in the portfolio. While the portfolio evolves towards its target, intelligence of the portfolio will have to monitor and evaluate

Figure 2. Unfolding a project portfolio (adapted from Espejo \& Reyes, 2011, p. 150)

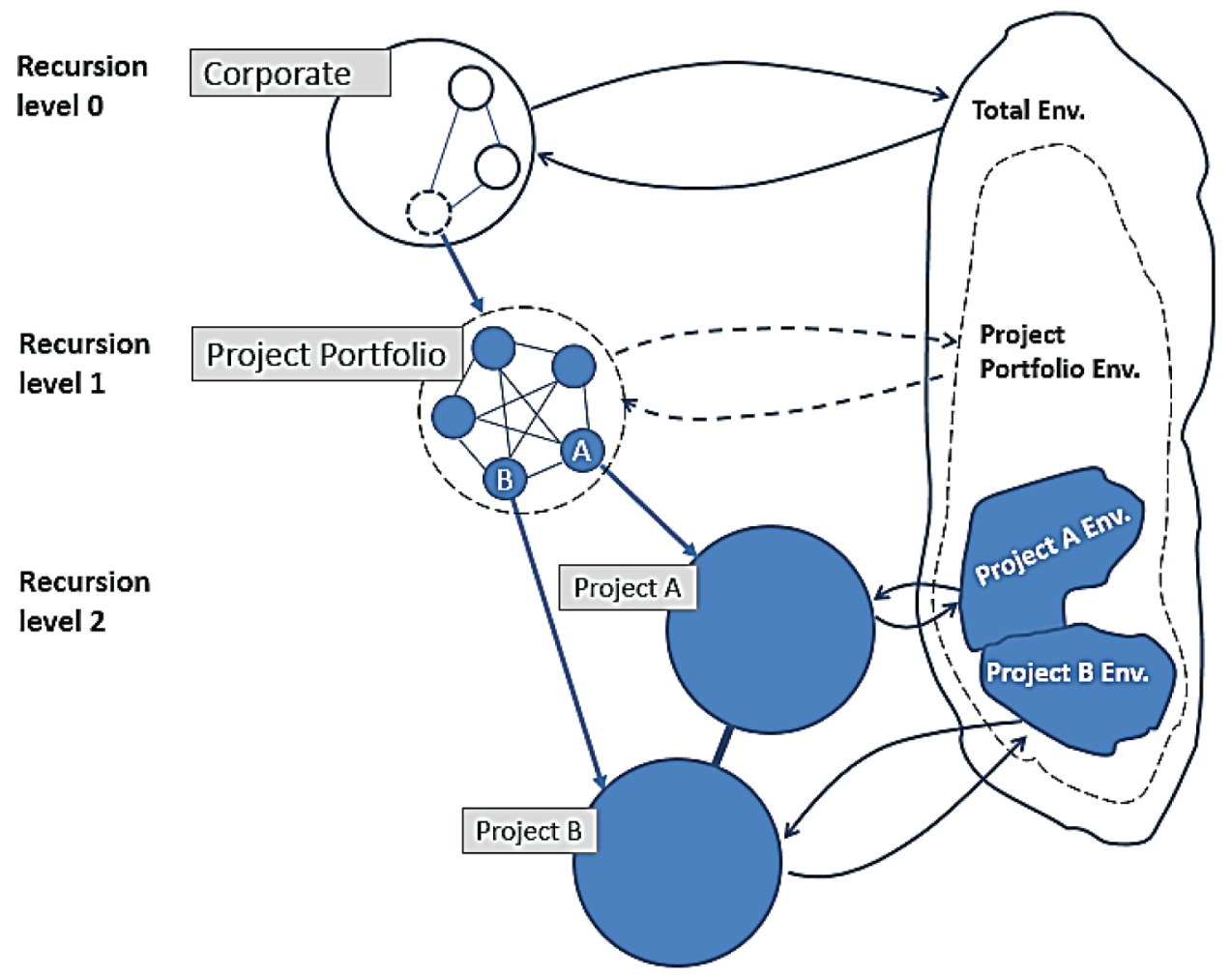


conditions that might need management attention (e.g. unexpected regulatory requirements, changed market demands, etc.). Coordination at this level of recursion is needed to maintain communication and collaboration among projects, and thereby assure portfolio-wide cohesion and consensus about portfolio goals.

On project level (recursion level 2); each project in the portfolio, such as projects A and B above, represents a whole stand-alone system that has its own relation with the outside world, strives for its viability but in the meantime contributes to the production and viability of the larger system, i.e. the portfolio. For example, assume there is a sequential dependency between two projects (A and B) in the portfolio, where project B cannot start unless project A completes. Not only would both projects be required to coordinate their actions to avoid deviating from the plan, but also both need to ensure that the portfolio deliverables are met. Here, the coordination function, at the portfolio level, plays a significant role both in ensuring that resources are properly allocated to the projects and that contact and trust are well established between the projects.

\section{Discussion of Empirical Results}

In this subsection, we examine the real-world IT/IS project portfolios presented in the empirical outcomes of the study. Each of the problem cases is discussed using the VSM approach.

\section{Case (1)}

This case revealed a problem about inability to determine future market directions that could influence both current and new services in the portfolio. Hence, it became nearly impossible to neither reach consensus on project priorities or plan projects in details nor critically assess their interdependent effects on the portfolio. To overcome this problem, an internal committee of experts was formed to think of possible scenarios concerning future market directions. The information was then used in decision-making regarding the projects and their possible interdependencies.

The state of the portfolio, from a systems perspective, can be diagnosed as being less predictable and less viable in terms of the large variety of the environment it faces. Ashby's law of requisite variety suggests that, in order for an organization to remain viable, it has to improve its own variety to meet the variety of the environment in which it exists (Ashby, 1964). This with reference to the VSM's intelligence function has to do with the organization's ability to obtain information about current activities in the market (e.g. information about competitors' price moves, information about new regulations) and/or predict future market behavior that may affect the organization (e.g. predict the impact of emerging technologies on the service industry). Accordingly, people related to the policy function can seize opportunities and/or decide how to deal with the threats in the market. For example, receiving information about competitors' plan regarding new products may lead to reprioritization of current projects in the portfolio. One way of amplifying organizational capacity to understand its environment could be, for example, through market research or through direct customer interactions. As is seen from the case description, the organization has made use of the skills and experience of its employees as well as the experience from earlier projects to augment its view on the market. From the above discussion, it follows that the intelligence function plays a central role in supporting portfolio planning and management, identifying interrelated projects and identifying possible interdependencies and synergies among projects. However, it is important to realize that although the organization can make good use of the information received from the external environment, the policy function would need as well to consider the dynamics of the internal environment.

\section{Case (2)}

This case reveals a problem situation of unexpected change in project scope that, in turn, caused disorder and delay to five other projects in the portfolio. All of the six projects were mutually dependent on each other for the purpose of developing a new complaint management system for the company. The change in project scope, therefore, created a situation of ambiguity and complexity within and 
across all the projects. A consequence of this has been that part of the portfolio was seriously out of control and that the portfolio failed to meet both time and financial criteria. Later, and as a solution, all of the six projects were combined into a single program so that they could be managed on a consistent basis and thus ensure that the portfolio got back on track.

The state of the portfolio, from a systems perspective, can be diagnosed as confronting a risk of losing internal coherence and control in part of its constituting projects. This can be attributed to two causes in combination: increased scope and complexity of projects and increased scope and complexity of inter-project relationships. The management of the portfolio was put to test in this case. Since it was unable to handle the upcoming situation, another organization was introduced to improve the internal control and coordination of the portfolio. In order to deal with this kind of interruptions within the system itself, allowing for the managers to take back control of the portfolio, the management roles would need to be further strengthened and communicated.

\section{Case (3)}

This case reveals a problem situation about a training project (TP) being delayed and significantly affected by another application development project (ADP) in the same portfolio. The impact on the TP was partly due to poor coordination with the ADP, but first and foremost, due to its sequential dependency on the ADP (i.e. the progress of the TP relied upon the timely output of the ADP). As a consequence, the portfolio suffered financial and time losses incurred in providing a practical solution to the problem.

According to case description, it can be argued that poor coordination between the two projects has resulted in a corresponding poor performance of the portfolio. However, it can also be argued that with sequential interdependency, according to Thompson (1967), there is always an element of potential contingency since each project must be readjusted if any other project failed to meet expectations. Espejo \& Reyes (2011) emphasized the importance of the VSM's coordination function in enabling connectivity and therefore cohesion among autonomous units. This has to do with establishing routines and agreements to support interproject communication and collaboration. Meanwhile, control and audit functions are necessary to maintain internal stability through continuous comparison of the actual results against the planned goals. For the coordination of a sequential interdependency, Thompson (1967) suggests using plans, and preset schedules, however frequent decisions and certain communication activities must be performed regularly. A remedy would be, for instance, to establish a mechanism through which it becomes possible to detect and correct deviations from goals.

\section{Case (4)}

This case reveals two main problem situations: having to deal with a wide range of technologies (and vendors) to come up with a design for the intended solution, and confronting a non-compliant project component that affects two projects in the portfolio and, consequently, also affects the development of the solution. In the first situation, the PPMO faced difficulty dealing with high variety and large number of possible combinations of system components to find the best solution. Beer (1985, p. 22) asserts that "high variety is necessarily cut down, or attenuate, to the number of possible states that the receiving entity can actually handle." Such evolving complexity can severely disrupt portfolio performance. To attenuate the complexity of the situation, the PPMO decided to rely only on technologies recognized as "best practices." This would probably help reduce the number of possible design options, which then can result in better decisions. In the second situation, the PPMO confronted delays in solution delivery due to incompatible project component. Components involved in the solution were supplied by different vendors but mainly through two separate projects in the same portfolio. Both projects were mutually dependent (meaning that each project's output is input for the other project). The decision can be regarded as a step towards a more viable project portfolio. The coordination function of the portfolio should address the project interdependencies, including 
the standards needed to make them work properly. Shared language, models and values, etcetera, are all serving this purpose. In this case, neglecting to define common standards undermined the technology interdependencies between the projects.

In summary, one common finding across these cases revealed a set of different sources of uncertainties that led to difficulties with handling PIs and therefore affected the viability of the portfolios. Among them are unpredictable changes in the environment, inability to anticipate future events, variability among technology options and poor understanding of human responsibilities in the whole portfolio. Overall, the findings showed that the VSM helped to explain the complex reality of PIs in the portfolios surveyed. This was possible because of the following factors:

1. The model offers a way to explore and explain, in greater detail, the structure of the system in focus and the environment in which the system is located; this helped in decomposing the portfolio down to parts (e.g. programs, projects, sub-projects, sub-sub-project, etc.) and interrelationships/ interdependencies relating these parts to one another and to the portfolio as a whole;

2. The model is recursive in nature, which means that it can be applied on all system levels; this helped to navigate through (and describe) hierarchical relationships between entities/ individuals comprising the portfolio and explain their roles and responsibilities through the life of the portfolio;

3. The model identifies interrelated functions (i.e. operations, coordination, control, audit, intelligence and policy) that contribute most to the viability of the system; this enhanced ability to critically reflect on issues and problems related to organizational design (e.g. barriers to effective communication, bureaucratic burdens, obstacles to effective resource allocation, etc.);

4. The model "allows to diagnose the structural mechanisms of an enterprise and use them as a platform for organizational design" (Espejo \& Reyes, 2011, p. 91); this can aid in designing organizational structures that enable the organization to perform effectively in the face of environmental uncertainty.

One of the limitations of the VSM is that it remains very sophisticated and hard to use for dayto-day management of all interdependencies between projects. This can be subject to further research.

\section{CONCLUSION}

In this study, we make use of Beer's VSM to combine the advantages of constructing a meaningful holistic view of the portfolio and observing the underlying interdependencies amongst the parts constituting it. Through the study, we provided more in-depth analysis of the PPM lifecycle and offered an alternative way to explain and diagnose various kinds of PIs. In examining the applicability of the model in real-world context, we used four problem cases collected through semi-structured interviews with PMO members in four IT-intensive organizations. As a result, the VSM found to be appropriate for analyzing and documenting difficulties of PIs, as it offers several benefits. First, it helps to construct a highly structured picture of the elements (i.e. projects, sub-projects, subsub-project, etc.) and the interrelationships comprising the portfolio, including the environment in which the portfolio is located. Second, it allows for a finer level of details concerning the roles and responsibilities of different functions (i.e. operations, coordination, control, audit, intelligence and policy) in the portfolio. Third, it supports critical reflection on problems related to organizational design. Forth, it provides a tool to plan, holistically, for establishing and maintaining the portfolio. In conclusion, we showed that the VSM can be used to analyze and find remedies to deal with complex situations involving PIs. Thus, the VSM can be adopted to help with diagnosing and handling PIs in IT/ IS project portfolio environments. As a future work in this area, we will investigate techniques to deal with the problems arising from PIs and enhance decision quality in complex IT/IS project portfolios. 


\section{REFERENCES}

Anantatmula, V., \& Webb, J. (2014). Critical chain method in traditional project and portfolio management situations. International Journal of Information Technology Project Management, 5(3), 67-83. doi:10.4018/ ijitpm.2014070104

Aritua, B., Smith, N. J., \& Bower, D. (2009). Construction client multi-projects - a complex adaptive systems perspective. International Journal of Project Management, 27(1), 72-79. doi:10.1016/j.ijproman.2008.02.005

Ashby, W. R. (1964). An introduction to cybernetics. London, UK: Methuen.

Bardhan, I., Bagchi, S., \& Sougstad, R. (2004). A real options approach for prioritization of a portfolio of information technology projects: A case study of a utility company. In Proceedings of the 37th Hawaii International Conference on System Sciences, Hawaii. doi:10.1109/HICSS.2004.1265499

Bardhan, I., Sougstad, R., \& Sougstad, R. (2004). Prioritizing a portfolio of information technology investment projects. Journal of Management Information Systems, 21(2), 33-60. doi:10.1080/07421222.2004.11045803

Bathallath, S., Smedberg, А., \& Kjellin, H. (2016a). Managing project interdependencies in IT/IS project portfolios: A review of managerial issues. International Journal of Information Systems and Project Management, $4(1), 67-82$.

Bathallath, S., Smedberg, Å., \& Kjellin, H. (2016b). Project interdependency management in IT / IS project portfolios: From a systems perspective. Procedia Computer Science, 100, 928-934. doi:10.1016/j. procs.2016.09.250

Bathallath, S., Smedberg, Å., \& Kjellin, H. (2017). Impediments to effective management of project interdependencies: A study of IT/IS project portfolios. Journal of Electronic Commerce in Organizations, 15(2), 16-30. doi:10.4018/JECO.2017040102

Beer, S. (1985). Diagnosing the system for organizations. John Wiley \& Sons Inc.

Bible, M. J., \& Bivins, S. S. (2012). Evaluating strategic project and portfolio performance. Journal of Project. Program \& Portfolio Management, 3(1), 10-30.

Blecic, I., Cecchini, A., \& Pusceddu, C. (2008). Constructing strategies in strategic planning: A decision support evaluation model. Operations Research, 8(2), 153-166. doi:10.1007/s12351-008-0014-6

Churchman, C. (1968). The systems approach. New York: Delacorte Press.

Cooper, R., Edgett, S. J., \& Kleinschmidt, E. J. (1999). New product portfolio management: Practices and performance. Journal of Product Innovation Management, 16(4), 333-351. doi:10.1016/S0737-6782(99)00005-3

Cooper, R., Edgett, S. J., \& Kleinschmidt, E. J. (2001). Portfolio management for new product development: Results of an industry practices study product innovation best practices series. Research and Development Management, 31(4), 361-380.

Daniel, E. M., Ward, J. M., \& Franken, A. (2014). A dynamic capabilities perspective of IS project portfolio management. The Journal of Strategic Information Systems, 32(2), 95-111. doi:10.1016/j.jsis.2014.03.001

Danilovic, M., \& Browning, T. R. (2007). Managing complex product development projects with design structure matrices and domain mapping matrices. International Journal of Project Management, 25(3), 300-314. doi:10.1016/j.ijproman.2006.11.003

Eilat, H., Golany, B., \& Shtub, A. (2006). Constructing and evaluating balanced portfolios of R\&D projects with interactions: A DEA based methodology. European Journal of Operational Research, 172(3), 1018-1039. doi:10.1016/j.ejor.2004.12.001

Engwall, M., \& Jerbrant, A. (2003). The resource allocation syndrome: The prime challenge of multi-project management? International Journal of Project Management, 21(6), 403-409. doi:10.1016/S0263-7863(02)00113-8

Espejo, R. (1994). What is systemic thinking? System Dynamics Review, 10(2-3), 199-212. doi:10.1002/ sdr.4260100208 
Espejo, R., \& Reyes, A. (2011). Organizational systems: Managing complexity with the viable system model. London: Springer Science \& Business Media. doi:10.1007/978-3-642-19109-1

Fliedner, T., \& Liesiö, J. (2016). Adjustable robustness for multi-attribute project portfolio selection. European Journal of Operational Research, 252(3), 931-946. doi:10.1016/j.ejor.2016.01.058

Formentini, M., \& Romano, P. (2011). Using value analysis to support knowledge transfer in the multi-project setting. International Journal of Production Economics, 131(2), 545-560. doi:10.1016/j.ijpe.2011.01.023

Ghaffari, M., \& Emsley, M. W. (2017). Buffer sizing in ccpm portfolios with different resource capacities. International Journal of Information Technology Project Management, 8(3), 40-51. doi:10.4018/ IJITPM.2017070103

Jackson, M. C. (1991). Systems methodology for the management sciences. New York: Plenum Press. doi:10.1007/978-1-4899-2632-6

Killen, C. P. (2013). Evaluation of project interdependency visualizations through decision scenario experimentation. International Journal of Project Management, 31(6), 804-816. doi:10.1016/j.ijproman.2012.09.005

Killen, C. P. (2017). Managing portfolio interdependencies: The effects of visual data representations on project portfolio decision making. International Journal of Managing Projects in Business, 10(4), 856-879. doi:10.1108/ IJMPB-01-2017-0003

Killen, C. P., \& Hunt, R. A. (2013). Robust project portfolio management: Capability evolution and maturity. International Journal of Managing Projects in Business, 6(1), 131-151. doi:10.1108/17538371311291062

Killen, C. P., Hunt, R. A., \& Kleinschmidt, E. J. (2007). Managing the new product development project portfolio: A review of the literature and empirical evidence. In Management of Engineering and Technology. Portland, Oregon.

Killen, C. P., \& Kjaer, C. (2012). Understanding project interdependencies: The role of visual representation, culture and process. International Journal of Project Management, 30(5), 554-566. doi:10.1016/j.ijproman.2012.01.018

Kundisch, D., \& Meier, C. (2011). IT/IS Project Portfolio Selection in the Presence of Project Interactions - review and Synthesis of the Literature. In Proceedings of the 10th International Conference on Wirtschaftsinformatik, Zürich (pp. 477-486).

Lee, J. W., \& Kim, S. H. (2001). An integrated approach for interdependent information system project selection. International Journal of Project Management, 19(2), 111-118. doi:10.1016/S0263-7863(99)00053-8

Levine, H. A. (2010). Project portfolio management: A practical guide to selecting projects. San Francisco, CA: John Wiley \& Sons.

Medaglia, A. L., Graves, S. B., \& Ringuest, J. L. (2007). A multiobjective evolutionary approach for linearly constrained project selection under uncertainty. European Journal of Operational Research, 179(3), 869-894. doi:10.1016/j.ejor.2005.03.068

Nyfjord, J., Bathallath, S., \& Kjellin, H. (2014). Conventions for Coordinating Large Agile Projects. In International Conference on Agile Software Development. Rome. Cham: Springer.

Parry, V. K. A., \& Lind, M. L. (2016). Alignment of business strategy and information technology considering information technology governance, project portfolio control, and risk management. International Journal of Information Technology Project Management, 7(4), 21-37. doi:10.4018/IJITPM.2016100102

Pons, D., \& Haefele, S. (2016). Team interactions for successful project management in small and medium-sized enterprises. International Journal of Information Technology Project Management, 7(2), 17-43. doi:10.4018/ IJITPM.2016040102

Rank, J., Unger, B. N., \& Gemünden, H. G. (2015). Preparedness for the future in project portfolio management: The roles of proactiveness, riskiness and willingness to cannibalize. International Journal of Project Management, 33(8), 1730-1743. doi:10.1016/j.ijproman.2015.08.002

Richards, L., \& Morse, J. M. (2012). Readme first from a user's guide to qualitative methods (3rd ed.). SAGE. 
Rungi, M., \& Hilmola, O. P. (2011). Interdependency management of projects: Survey comparison between Estonia and Finland. Baltic Journal of Management, 6(2), 146-162. doi:10.1108/17465261111131785

Schoderbek, P. P., Schoderbek, C. G., \& Kefalas, A. G. (1990). Management systems: Conceptual considerations. Homewood, IL: BPI Irwin.

Teller, J., Unger, B. N., Kock, A., \& Gemünden, H. G. (2012). Formalization of project portfolio management: The moderating role of project portfolio complexity. International Journal of Project Management, 30(5), 596-607. doi:10.1016/j.ijproman.2012.01.020

Thompson, J. D. (1967). Organizations in Action. Chicago: McGraw-Hill.

Verma, D., \& Sinha, K. K. (2002). Toward a theory of project interdependencies in high tech R \& D environments. Journal of Operations Management, 20(5), 451-468. doi:10.1016/S0272-6963(02)00024-4

Voss, M., \& Kock, A. (2013). Impact of relationship value on project portfolio success - investigating the moderating effects of portfolio characteristics and external turbulence. International Journal of Project Management, 31(6), 847-861. doi:10.1016/j.ijproman.2012.11.005

Webster, J., \& Watson, R. T. (2002). Analyzing the past to prepare for the future: Writing a literature review. Management Information Systems Quarterly, 26(2), xiii-xxiii.

Sameer Bathallath is a PhD candidate in the Department of Computer and Systems Sciences at Stockholm University, Sweden. He has several years of industrial experience in ICT sector. His research interest includes PMO practices for IT/IS project portfolio management, applying systems thinking and cybernetics to managerial problem-solving. His research focus is centered on helping PMOs deal with daily challenges concerning the ITinterdependencies in their project portfolios.

Asa Smedberg is an associate professor in the Department of Computer and Systems Sciences at Stockholm University, Sweden. She holds a PhD degree in computer and systems sciences. Her research interests include systems theory, holistic system design, IT-management, community informatics and the use of ICT for continuous learning, with a special focus on applications in e-health and project portfolio management. She is the author of a series of international publications, a book editor, and she serves on editorial review boards and as a committee member of international conferences.

Harald Kjellin is a professor in system science at the department of Computer and System Sciences at Stockholm University. He has been responsible for research projects in Artificial Intelligence that resulted in systems that were used nationwide in Sweden. His research has, since 1989, dealt with acquiring and organizing knowledge in order to make it suited for being reused. Lately his research is focused on heuristics for managing project portfolios. 